\title{
Recurrent Inflammatory Myoblastic Tumour of the Vocal Cord: A Rare Case Report from Malaysia
}

\author{
Ihab E. Ali ${ }^{*}$, Farid R², Suhaila R², Keng-Yin Loh ${ }^{3}$ \\ ${ }^{1}$ ENT Department, Taylor's University, Subang Jaya, Malaysia \\ ${ }^{2}$ ENT Department, Hospital Shah Alam, Shah Alam, Malaysia \\ ${ }^{3}$ Family Medicine Department, Taylor's University, Subang Jaya, Malaysia \\ Email: ^Ihab.Ali@taylors.edu.my, jernk8177@gmail.com, Suhaila1026@gmail.com, Kengyin.Loh@taylors.edu.my
}

How to cite this paper: Ali, I.E., Farid R, Suhaila R and Loh, K.-Y. (2021) Recurrent Inflammatory Myoblastic Tumour of the Vocal Cord: A Rare Case Report from Malaysia. International Journal of Otolaryngology and Head \& Neck Surgery, 10, 102-106.

https://doi.org/10.4236/ijohns.2021.102011

Received: February 18, 2021

Accepted: March 28, 2021

Published: March 31, 2021

Copyright $\odot 2021$ by author(s) and Scientific Research Publishing Inc. This work is licensed under the Creative Commons Attribution International License (CC BY 4.0).

http://creativecommons.org/licenses/by/4.0/ (c) (i) Open Access

\begin{abstract}
Inflammatory myoblastic tumour (IMT) is a rare benign neoplasm that can affect any part of the body including the head and neck. When it is affecting the head and neck region, the clinical presentations can mimic other common head and neck pathology. If the tumour involves the upper airway it can cause stridor and hoarseness. Other presenting features are neck swelling and dysphagia. This tumour may mimic other chronic granulomatous diseases. This case report described a rare IMT arising from the vocal cord and presents with hoarseness and stridor for six months duration. The patient has no known risk factors. Despite surgical resection, the tumour recurred within six month and further surgical resection was performed, but yet the tumour recurred after one year following second surgery. She was then further treated with mass excision by Endolaryngeal Microsurgery (ELMS) with steroid laryngeal injection. Currently she is still being followed up and remains asymptomatic.
\end{abstract}

\section{Keywords}

Inflammatory, Myoblastic, Recurrent

\section{Introduction}

Inflammatory myoblastic tumour (IMT) is a rare benign neoplasm that can affect any part of the body. This tumour is characterized by the mixture of inflammatory cells such as plasma cells, lymphocytes and eosinophils, and bland spindle cells without nuclear atypia [1] in the body. Reported cases of IMT affecting the head and neck region are not many. If IMT is arising in the upper 
airway, it commonly presents with feature of upper airway obstruction such as stridor and hoarseness. It can mimic other common upper airway diseases such as infection, granulomatous disease or malignancy. The following case report illustrated a young female patient from Malaysia who presented with stridor and hoarseness and finally confirmed IMT arising from vocal cord. Despite surgical resection the tumour recurred two times within 2 years.

\section{History}

A 25-year-old lady was referred from the primary care clinic to otolaryngology clinic with the history of progressive hoarseness of voice and dysphagia for six-month duration. It was also associated with episodic breathlessness. She has no history of sore throat, rhinitis or pain in the oral cavity. There is no history of weight loss, fever and no known family history of malignancy. She is a housewife and no history of voice abuse. No history of smoking or alcohol consumption.

On examination, the patient looks comfortable and not in any distress. Mild stridor was noted, and her respiratory rate was 20 breath per minute and not cynosed. There are no obvious abnormalities noted on external examination of her head and neck region. Examination of the cervical region did not reveal any palpable lymph nodes.

Further examination by flexible laryngeal scope revealed a huge polyp-like mass on the left true vocal fold (Figure $1 \&$ Figure 2). The mass measured about $2 \times 1 \mathrm{~cm}$ and it almost obstructing the laryngeal inlet. Endo-laryngeal microsurgery (ELMS) was then performed, and the mass was totally excised. The mass excised as single block measured $2.0 \times 1.5 \times 0.5 \mathrm{~cm}$ and sent for histopathological examination. Her basic laboratory investigations showed all parameters are within normal range (Table 1). Screening for tuberculosis includes sputum direct smear for acid fast bacilli and culture for tuberculosis all revealed negative results.

The result from histopathological examination (HPE) of the specimen was consistent with inflammatory myofibroblastic tumou (IMT). She was discharged from hospital and recovery was uneventful.

\section{Progress}

About six months after the surgery the hoarseness recurred. Repeated laryngeal scope showed evidence of recurrent of the tumour. She underwent similar procedure and HPE was still consistent with IMFT. Following the second surgery she was asymptomatic for about a year but then the hoarseness recurred for another episode. Further examination revealed a similar recurrent mass at the same site. This mass was excised by Endolarygeal Microsurgery (ELMS) with steroid laryngeal injection and put on omeprazole tablet $20 \mathrm{mg}$ for 6 weeks. Post-operative HPE was consistent with IMT.

Subsequent follow up for more than 2 years and she remains asymptomatic with no evidence of recurrent or malignant transformation. She is still followed up now and she is well. 


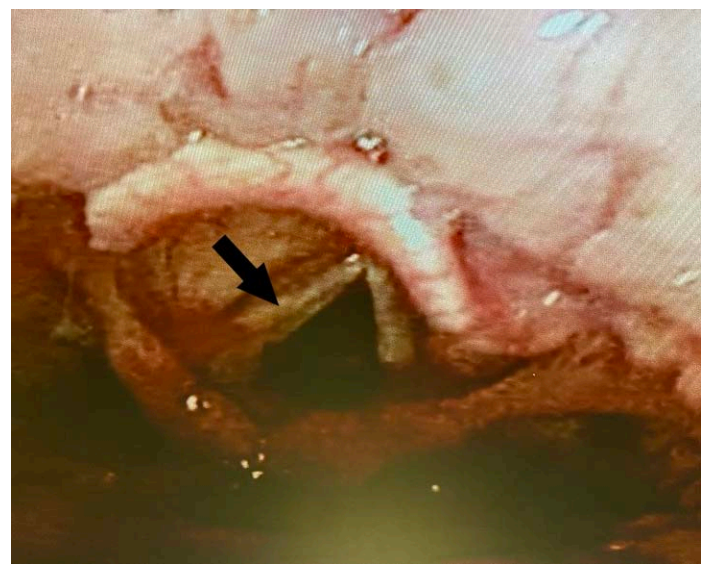

Figure 1. Laryngoscopic view of the mass arising from left vocal fold.

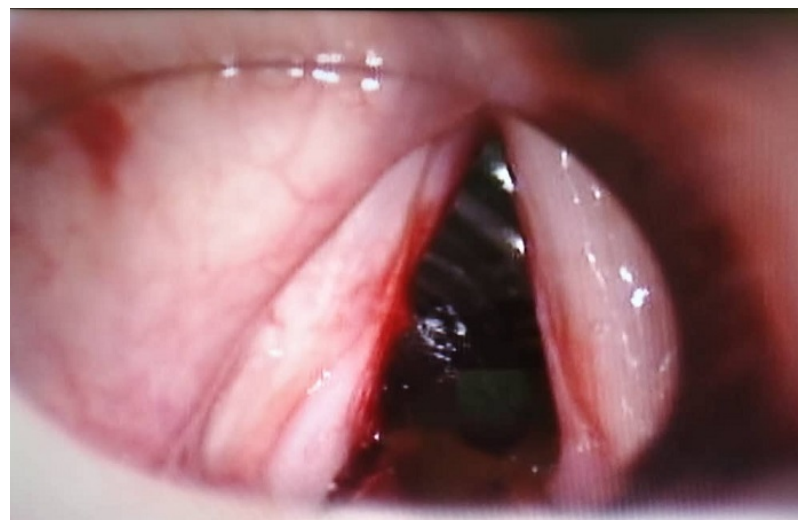

Figure 2. Close-up view of the mass showing obstruction to the laryngeal inlet.

Table 1. Laboratory test results.

\begin{tabular}{ccc}
\hline Test & Results & Normal reference \\
\hline Hemoglobin & $13.0 \mathrm{~g} \%$ & $11-14 \mathrm{~g} \%$ \\
Urea & $3.1 \mathrm{mmol} / \mathrm{L}$ & $2.5-9 \mathrm{mmol} / \mathrm{L}$ \\
Creatinine & $67.0 \mathrm{umol} / \mathrm{L}$ & $60-120 \mathrm{umol} / \mathrm{L}$ \\
Sodium & $140.0 \mathrm{mmol} / \mathrm{L}$ & $135-145 \mathrm{mmol} / \mathrm{L}$ \\
Potassium & $4.0 \mathrm{mmol} / \mathrm{L}$ & $3.5-4.5 \mathrm{mmol} / \mathrm{L}$ \\
Total white cell count & $11.2 \times 10^{9} / \mathrm{L}$ & $4-11 \times 10^{9} / \mathrm{L}$ \\
Fasting serum glucose & $4.5 \mathrm{mmol} / \mathrm{L}$ & $4-6 \mathrm{mmol} / \mathrm{L}$ \\
\hline
\end{tabular}

Sputum direct smear for acid fast bacilli NEGATIVE; Sputum culture for acid fast bacilli NEGATIVE; Mantoux test Non reactive.

\section{Discussion}

Inflammatory myofibroblastic tumor (IMT) is an uncommon benign neoplasm. It can affect any part of the body and commonly it mimics malignant neoplasm in clinical presentation, radiological and histopathologically. Typically its histology characterized by mixture of inflammatory cells such as plasma cells, lymphocytes and eosinophils, and bland spindle cells without nuclear atypia [1]. 
Sometimes it may also present with necrosis, bleeding or even calcification within. There are also various medical terminologies used to describe this tumor such as inflammatory pseudotumor, fibrous xanthoma, plasma cell granuloma, pseudosarcoma, lymphoid hamartoma, myxoid hamartoma, inflammatory myofibrohistiocytic proliferation [2].

Although many hypotheses have been described to explain its pathogenesis, such as reactive, infections, autoimmune and neoplastic processes, the etiology of most IMT remains unknown. In recent years more reports have been published showing cases of recurrences and metastasis and cytogenetic evidence of acquired clonal chromosomal abnormalities [3] [4]. Common sites of this tumour in the body are the lungs, liver and gastrointestinal tract. However this tumour can be found in any other part of the body including the head and neck region. IMT has been reported in epiglottis, endolarynx, parapharyngeal spaces, maxillary sinus, submandibular region and oral cavity [3].

Recent research on IMT postulated genetic factor may be a cause in the pathogenesis. Among the recent findings include its association with chromosome 2p23 involving the Anaplastic Lymphoma Tyrosine Kinase (ALK) receptor and its fusion with clathrin heavy chains. This association has been demonstrated in up to $50 \%$ of soft tissue IMTs [5].

IMT involving upper air way is rare. If it occurs at the upper airway the common clinical features are stridor and hoarseness, these clinical presentations can easily mimic other common upper air way obstruction such as malignant squamous cell carcinoma of the larynx, vocal cord nodule or other granulomatous diseases such as tuberculosis. When it affecting upper airway usually it is less aggressive but is known to be associated with local invasion and recurrent despite of surgical treatment [6]. This case presented here illustrated similar problem.. Currently local surgical resection remains the treatment of choice [7]. Published case reports had repeatedly shown recurrent and long term malignant transformation is known complications with mortality [8]. Therefore long term follow up is necessary due to the nature of this tumour to recur despite of surgical resection and the need to evaluate any future malignant transformation.

\section{Conclusion}

This case report demonstrated a rare benign tumour IMT affecting the vocal cord which causes stridor and hoarseness. Once we excluded other common causes of upper respiratory tract that causes stridor, one must consider the possibility of rare tumour of the head and neck region. The diagnosis is clear with tissue biopsy by laryngoscopy. But the challenges in this tumour are its recurrence and potential of future malignant transformation that the treating doctor must be aware of.

\section{Conflicts of Interest}

The authors declare no conflicts of interest regarding the publication of this paper. 


\section{References}

[1] Gleason, B.C. and Hornick, J.L. (2008) Inflammatory Myofibroblastic Tumours: Where Are We Now?. Journal of Clinical Pathology, 61, 428-437. https://doi.org/10.1136/jcp.2007.049387

[2] Poh, C.F., Priddy, R.W. and Dahlman, D.M. (2005) Intramandibular Inflammatory Myofibroblastic Tumour: A True Neoplasm or Reactive Lesion? Oral Surgery, Oral Medicine, Oral Pathology, Oral Radiology, and Endodontology, 100, 460-466. https://doi.org/10.1016/j.tripleo.2004.07.005

[3] Margaret, S., Silloo, B.K. and Gnepp, D.R. (2001) Nonsquamous Pathology of the Larynx, Hypopharynx, and Trachea. In: Gnepp, D.R., Ed., Diagnostic Surgical Pathology of the Head and Neck (4th ed., pp. 287-288). New York: W.B. Saunders Company.

[4] Volker, H.U., Scheich, M., Holler, S., Strobel, P., Hagen, R., Hermenlink, H.K., et al. (2007) Differential Diagnosis of Laryngeal Spindle Cell Carcinoma and Inflammatory Myofibroblastic Tumour: Report of Two Cases with Similar Morphology. Diagnostic Pathology, 2, 1-7. https://doi.org/10.1186/1746-1596-2-1

[5] Nikitakis, N.G., Brooks, J.K., Frankel, B.F., Papadimitriou, J.C. and Sauk, J.J. (2004) Inflammatory Myofibroblastic Tumour of Oral Cavity: Review of Literature and Presentation of an ALK Positive Case. Oral Surgery, Oral Medicine, Oral Pathology, Oral Radiology, and Endodontology, 98,197-198.

https://doi.org/10.1016/j.tripleo.2004.06.017

[6] Martines, F., Martines, E., Casamitjana Claramunt, F. and Perelló Scherdel, E. (2007) Inflammatory Myofibroblastic Tumor of the Larynx. Case Report. Acta oto-rino-laringológica ibero-americana, 34, 201-208.

[7] Chen, Y.F., Zhang, W.D., Wu, M.W., Ou-Yang, D. and Zhang, Q. (2011) Inflammatory Myofibroblastic Tumor of the Head and Neck. Medical Oncology, 28, S349-S353. https://doi.org/10.1007/s12032-010-9729-3

[8] Liu, Y., Liu, L., Huang, D., Wang, J., Wu, W., Liu, M., Zhao, J., Zhao, P. and An, Y. (2014) Clinical Features of Inflammatory Myofibroblastic Tumor in the Head and Neck. Zhonghua Er Bi Yan Hou Tou Jing Wai Ke Za Zhi, 49, 35-38. 